\title{
Optimal water allocation for an alpine hydropower system under changing scenarios
}

\section{Journal Article}

\section{Author(s):}

Alfieri, Lorenzo; Perona, Paolo; Burlando, Paolo

Publication date:

2006-10

Permanent link:

https://doi.org/10.3929/ethz-b-000022522

Rights / license:

In Copyright - Non-Commercial Use Permitted

Originally published in:

Water Resources Management 20(5), https://doi.org/10.1007/s11269-005-9006-y 


\title{
Optimal Water Allocation for an Alpine Hydropower System Under Changing Scenarios
}

\author{
LORENZO ALFIERI ${ }^{1}$, PAOLO PERONA ${ }^{2}$ and PAOLO BURLANDO ${ }^{2}$ \\ ${ }^{1}$ Department of Hydraulics, Transports and Civil Infrastructures, Politecnico di Torino, Turin, Italy; \\ ${ }^{2}$ Institute of Hydromechanics and Water Resources Management, Swiss Federal Institute of \\ Technology (ETH), Zurich, Switzerland \\ (author for correspondence, e-mail: perona@ihw.baug.ethz.ch)
}

(Received: 1 June 2005; in final form: 29 October 2005)

\begin{abstract}
The operating rules of water allocation in the alpine OFIMA hydropower network of the Maggia River basin (Canton Tessin, Switzerland) are investigated in response to changes in the production policy and environmental and climatic factors. The study was carried out by means of a nonlinear programming approach where the objective function is approximated to a quadratic form with linear constraints, and implemented on a monthly time scale. Two systemís configurations with different details were accordingly investigated and compared to assess the response of the hydropower network to changes in the production policy, in the magnitude of the inflows and to different environmental requests. The optimal solution of water allocation corresponding to the new hypothetical production policy shows marked differences but similar benefits when compared to the one of the present operating rules, thus suggesting the good flexibility of the real network under such change. In its whole, this paper therefore highlights the importance of supporting strategic decisions by means of informatics tools and, in addiction, it provides a useful case study to test the performances of the software AQUARIUS implementing such a nonlinear programming technique.
\end{abstract}

Key words: water allocation, optimization problem, quadratic programming, AQUARIUS, climate change

\section{Introduction}

The apparent increase of seasonal variability of the hydrological cycle and the expected effects of potential climate changes on the allocation of water uses represent an important issue in water resources management (Frederick and Schwarz, 1999, Snelder and Biggs, 2002). Hydropower plants, for instance, hold a critical position, especially when they are located in alpine environments. Such plants show a well-known flexibility in following the market energy requests thanks to their ability in rapidly switching on and off the turbines. This feature is closely related to the ability of efficiently planning the storage of water in the upstream reservoirs. In turn, this depends on the local hydrological behaviour and the forecast of the related time series. The assumption of stationarity, which is generally postulated to 
derive the operational rules of these water systems, may become therefore easily questionable under changing climatic scenarios. Under this perspective, the search for more appropriate operational rules for the power plants must be considered, being aware that this could influence the future production of the hydropower stations. Accordingly, the feedback coming from a correct planning strategy may help to reduce environmental, social and economical stresses, which play a considerable role for the future life of such hydropower plants. Numerous examples have been so far detected and classified (Pohl, 2002) where a concurrence of factors decided upon the interruption of the activity, the fate of the related reservoirs (Jordan, 1999, Pohl, 2002) and the consequences for the fluvial ecosystem (Bushaw-Newton et al., 2002).

Whether on one hand the search for the most efficient energy production is pursued, on the other hand there are risks and possible consequences of altering the regime of the local water courses (e.g., on the well-being of the riverine ecotone and, eventually on the recharging mechanism of the groundwater system (Franković, 1994)). The problem of optimizing the water allocation between users becomes therefore particularly important for both planning an efficient energy production strategy and redistribution of the water releases for the preservation of the downstream ecological indexes (Brown et al., 1990, Diaz et al., 1992, Jordan, 1999, Brown et al., 2002).

We investigate the Maggia River basin, which is regulated by 8 reservoirs that drain water through 35 intakes, and supply 6 hydropower plants. The network of hydropower plants (OFIMA Company) has long been subjected to questions related to the eco-hydrological impact of the water abstraction caused by the dams. To this end, a multidisciplinary project (MaVal, www.maggia.ethz.ch) involving two of the authors (P.B and P.P) is currently running to investigate the ecohydrology of the riverine corridor, with respect to the operating rules that still assure an efficient hydropower production. The present work concerns more with this second aspect. In particular, we analyze both the robustness and flexibility of the actual network against changes in the production policy of its operating rules. The new picture that is here considered concerns with the abandoning of a production strategy based on a local economical market in favor of a global one. That is, a production not predominantly driven by local requests of energy, but rather free of vending them to a bigger market. The rather complex interconnection between the plants of the OFIMA network makes the question of water allocation among such users an interesting case study. This type of problem is generally nonlinear and has been tackled here by using the technique of sequential quadratic programming that is implemented in the software AQUARIUS (Diaz et al., 1997). Since the perspective of such a change can markedly affect the hydropower production both at a monthly and annual time scales, the optimization of new strategies is a key issue that must be carefully planned in advance in order to assure an efficient management of the whole system. All these aspects are specifically addressed and will be also analyzed with respect to different climatic and environmental scenarios. 


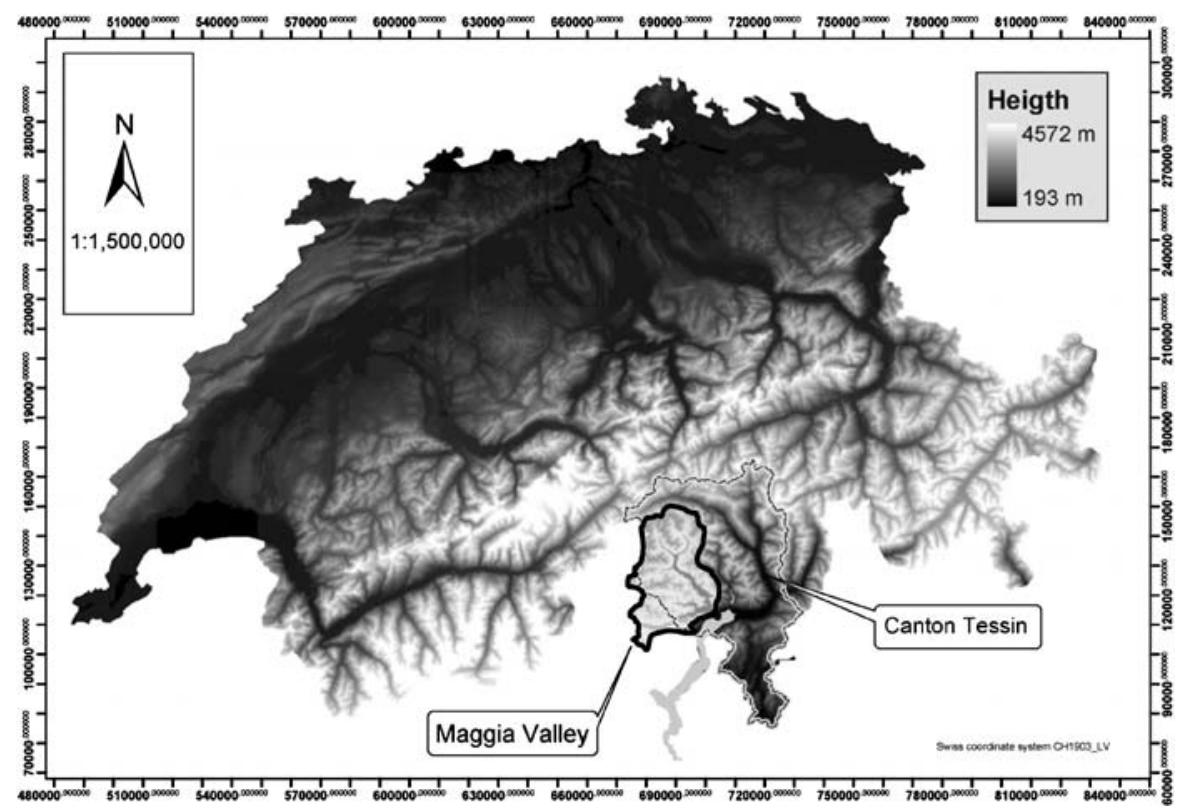

Figure 1. Location of the Maggia valley in Switzerland.

\section{The Environment and the OFIMA Network}

The Maggia valley is located in the southern part of the Swiss alps (Figure 1). The topography of the central part of the valley is characterized by steep slopes, which end on a $2-3 \mathrm{~km}$ wide alluvial floodplain. The alluvial material in situ has high permeability, and a location of the deep bedrock around $-120 \mathrm{~m}$, which rapidly rises up to the surface in the lower end of the valley. The Maggia valley has a main water course, i.e. the Maggia river, whose connection with the groundwater table is characterized by pronounced infiltration and exfiltration zones. The river morphology shows either single threads or evident braided reaches. This latter feature characterizes the river for about three kilometers around the centre of the valley, and this area has the most rich and interesting ecotone of the valley. The Maggia river basin has a surface of $568 \mathrm{~km}^{2}$ and an elevation ranging between 200 and $3300 \mathrm{~m}$ a.s.l. In the upper part of the valley, the two glaciers of Basodino and Cavagnoli, together with the annual solid precipitation, contribute to determine the glacio-nival hydrological regime of the whole basin.

The OFIMA network (see, for instance the corresponding planar scheme in Figure 2) collects nearly all the runoff of the Maggia valley and partially those of the next Aegina and Bedretto ones by means of 35 water intakes. Water is then delivered to 8 reservoirs ( 7 artificial and 1 natural) throughout a network of over $140 \mathrm{~km}$ of galleries. Water is afterward turbinated in 6 hydropower plants, two of 


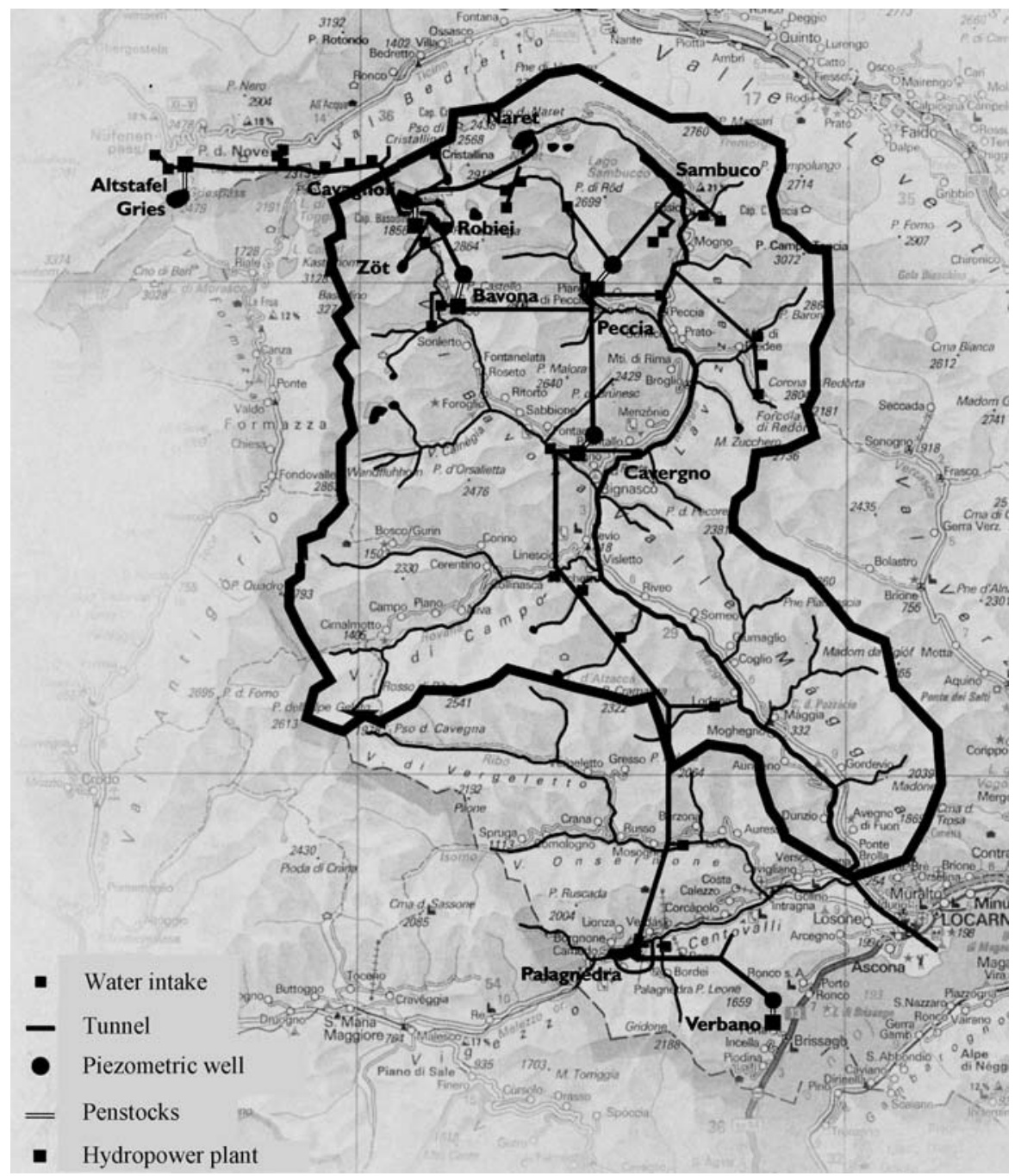

Figure 2. Map of the OFIMA hydropower plants and natural river network. The bold line indicates the contours of the Maggia river basin.

which serve as pumping stations as well. Some of the main technical characteristics of the reservoirs and the hydropower stations are summarized in Table I and II. The system of turbines is both in parallel and in cascade interconnected (Figure 3), and develops a total power of $600 \mathrm{MW}$, which allows to produce an annual average amount of energy of about $1300 \mathrm{GWh}$. This quantity represents the main source of electrical supply of the whole Canton Tessin. Further information is public on the World Wide Web site www.ofima.ch. 
Table I. Technical characteristics of the dams and the reservoirs. Elevation is intended to be the water surface at the maximum capacity

\begin{tabular}{lllclcc}
\hline Name & $\begin{array}{l}\text { Year of } \\
\text { construction }\end{array}$ & Type & $\begin{array}{l}\text { Height } \\
{[\mathrm{m}]}\end{array}$ & $\begin{array}{l}\text { Elevation } \\
{[\mathrm{m} \text { a.s.1. }]}\end{array}$ & $\begin{array}{l}\mathrm{V}_{\text {net }} \\
{\left[10^{6} \mathrm{~m}^{3}\right]}\end{array}$ & $\begin{array}{c}\mathrm{V}_{\text {tot }} \\
{\left[10^{6} \mathrm{~m}^{3}\right]}\end{array}$ \\
\hline Gries & 1965 & Gravity & 60 & 2386 & 18 & 18.7 \\
Robiei & 1967 & Gravity & 68 & 1940 & 4.8 & 6.9 \\
Zot & 1967 & Arch & 36 & 1940 & 1.56 & 1.60 \\
Cavagnoli & 1968 & Arch & 111 & 2310 & 27.8 & 29.1 \\
Naret I, II & 1970 & Arch, Gravity & 80,40 & 2310 & 31.1 & 31.6 \\
Sambuco & 1956 & Arch/Gravity & 130 & 1461 & 63.2 & 64.2 \\
Palagnedra & 1952 & Earth & 72 & 486 & 2.0 & 4.25 \\
Sfundau & - & Natural lake & - & 2386 & 3.6 & - \\
Peccia & - & Compensation basin & - & 1032 & 0.11 & 0.11 \\
\hline
\end{tabular}

$V_{\text {tot }}$ and $V_{\text {net }}$ state for the total and the net volume (i.e. excluding the minimum unused capacity) of the reservoirs, respectively.

Table II. Technical characteristics of the hydropower plants

\begin{tabular}{lllllcl}
\hline Name & Turbine & Pumping & $\begin{array}{l}\text { Number of } \\
\text { turbines }\end{array}$ & $\begin{array}{l}\text { Head } \\
{[\mathrm{m}]}\end{array}$ & $\begin{array}{l}\text { Nom. power } \\
{[\mathrm{MW}]}\end{array}$ & $\begin{array}{l}\text { Turb. speed } \\
{[\mathrm{Rpm}]}\end{array}$ \\
\hline Altstafel & Francis & No & 1 & 384 & 9 & 1500 \\
Robiei & Francis & Yes & $4+1$ & 338 & 150 & 1000 \\
Bavona & Pelton & No & 2 & 887 & 138 & 428 \\
Peccia & Pelton & Yes & 2 & 381 & 48 & 300 \\
Cavergno & Pelton & No & 4 & 489 & 104 & 375 \\
Verbano & Francis & No & $4+1$ & 255 & 106 & 500 \\
\hline
\end{tabular}

\section{The Hydropower Network Model}

\subsection{METHODOLOGY AND THE SOFTWARE AQUARIUS}

Managing an efficient strategic planning of water resources requires an approach by nonlinear programming and optimization techniques. The shape of the economical demand functions that are applied to each water use determines a complex nonlinear objective function, which must be studied together with both physical and operational constraints. The general nonlinear nature of the problem can be stated as follows: let us assume the jth user can price the quantity of water $x$ that is being used, then a marginal cost $b$ can be defined as

$$
b_{j}(x)=f_{j}(x)
$$

In the context of dynamic programming the optimization of the total benefit of the $j$ th user $B_{j}$ will depend on the quantity of water that is being allocated within 


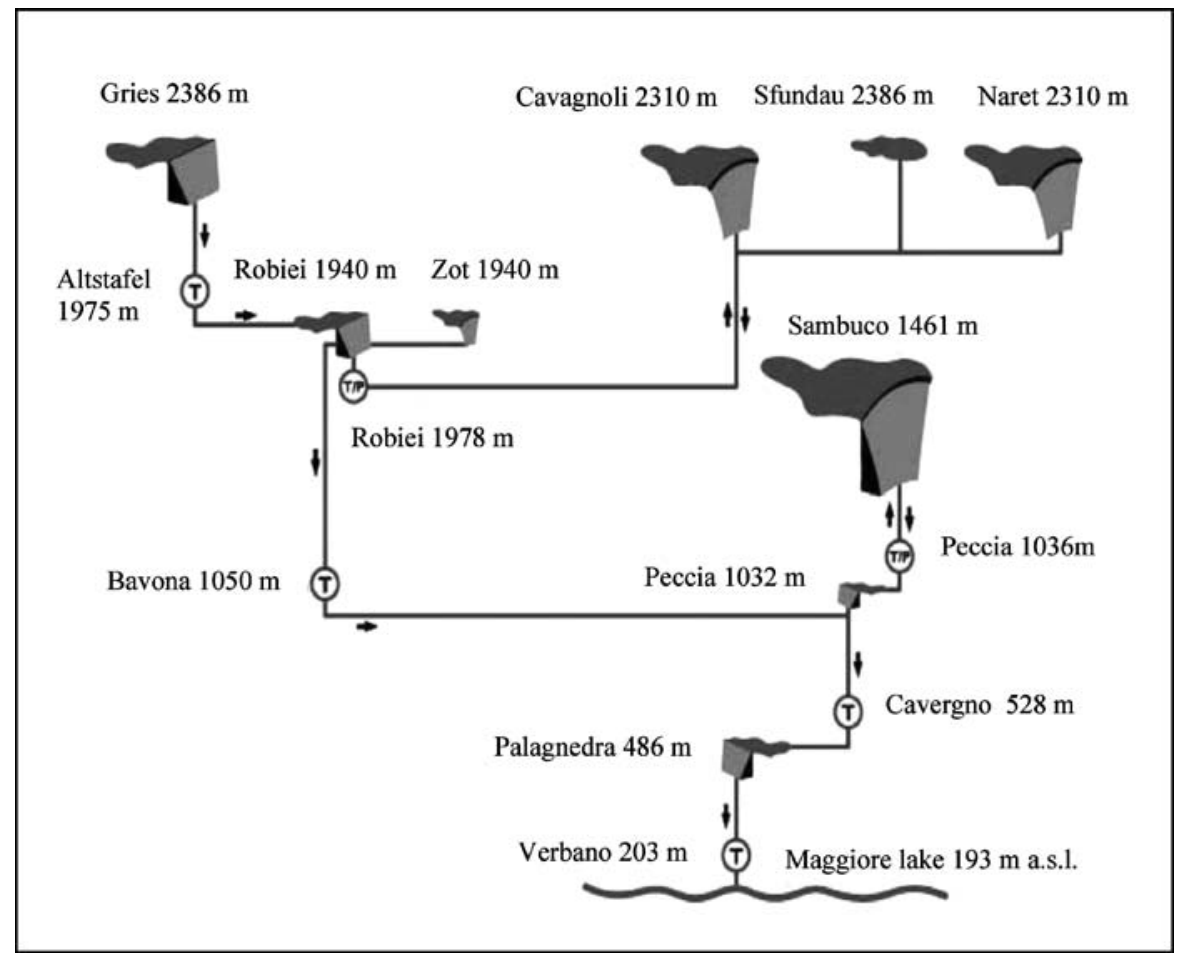

Figure 3. Representative sketch of the interconnections between the power plants and the related reservoirs.

a given time period $T$ (optimization horizon)

$$
B_{j}=\int_{0}^{a_{j}} f_{j}\left(x_{j}\right) d x_{j}
$$

where $a_{j}$ is the level of allocation of the resource for that user. The whole nonlinear objective function, that is the total benefit function $f(\mathbf{x})$, is the sum over all the $N$ water uses and all the $T$ time intervals of the single benefits $B_{j}$

$$
f(\mathbf{x})=\sum_{i=1}^{T} \sum_{j=1}^{N} \int_{0}^{a_{i j}} f_{i j}\left(x_{i j}\right) d x_{i j},
$$

plus a possible ensemble of bounded variables, equality and inequality constraints. Such problems involving constrained optimization, are usually solved by using nonlinear programming techniques. A milestone among them is represented by sequential quadratic programming (see also (Fletcher, 1980, Diaz et al., 1997) for 
further details), which implies that the following optimization problem is solved

$$
\begin{aligned}
\left.\operatorname{Max}\right|_{\mathbf{x}}[f(\mathbf{x}) & \left.=w+\mathbf{c}^{\mathbf{T}} \mathbf{x}+\frac{\mathbf{1}}{\mathbf{2}} \mathbf{x}^{\mathbf{T}} \mathbf{Q} \mathbf{x}\right] \\
\mathbf{g}(\mathbf{x}) & =\mathbf{A x} \geq \mathbf{r}, \\
\mathbf{x} & \geq 0
\end{aligned}
$$

where both inequality constraints (5) and nonnegativity conditions (6) are imposed. Thereupon, $\mathbf{r}$ is a vector containing the constraints, $\mathbf{A}$ is the matrix of the constraint coefficients, $\mathbf{Q}$ is a square matrix of dimension $N \times N$, which components can be obtained together with those of $\mathbf{c}$ and $w$ from a Taylor expansion of the total benefit function truncated beyond the second order terms. The software AQUARIUS (freely available online for research purposes at http://www.fs.fed.us/rm/value/aquarius.html, together with the related documentation (Diaz and Brown, 1997, Diaz et al., 1997, Hickey and Diaz, 1999)) implements such a technique proficiently and was therefore used here. While for the complete mathematical details the reader is referred to the related literature (Diaz and Brown, 1997, Diaz et al., 1997), here it is however worth to shortly recall the main characteristics of the software.

AQUARIUS solves water allocation problems using an economical criterion that is based on Marshallian demand functions, i.e. only involving the demand that producers base on a given budget. It is an analysis framework that uses an Object Oriented Programming (OOP) language $(\mathrm{C}++)$ to build the network of the water system being analyzed. The goal pursued by the software is to optimize the water allocation in the network on an economic efficiency criterion. In particular, the nonlinear programming problem $(3,4-6)$ is solved i) by pursuing those decisions that lead to an equal marginal value of water among the users (Diaz et al., 1992, Diaz and Brown, 1997), and ii) by continuously reallocating the quantity of water in respect of the specified constraints, and without any feedback from the outflows that may result from the optimization or from externally imposed preferences (Diaz et al., 1997).

AQUARIUS can handle different types of functions to represent the marginal benefit (i.e., constant, linear, exponential), thus suggesting the possibility to manage with problems that show evident economical scaling laws. Moreover, optimization over multiple horizons (period of optimization) can be explored by AQUARIUS, together with the possibility of overlapping them of a given time span (overlapping period). This characteristic seems to limit the propagation of end effects among each optimization horizon (Diaz et al., 1997). Equation 3 is then sequentially reduced to a quadratic form via a Taylor series after an Initial Feasible Solution (IFS) is found. The optimum is pursued by using a sequential approximation technique in order to find the maximum of the total benefit function in respect of the imposed constraints (Diaz and Brown, 1997, Diaz et al., 1997). 


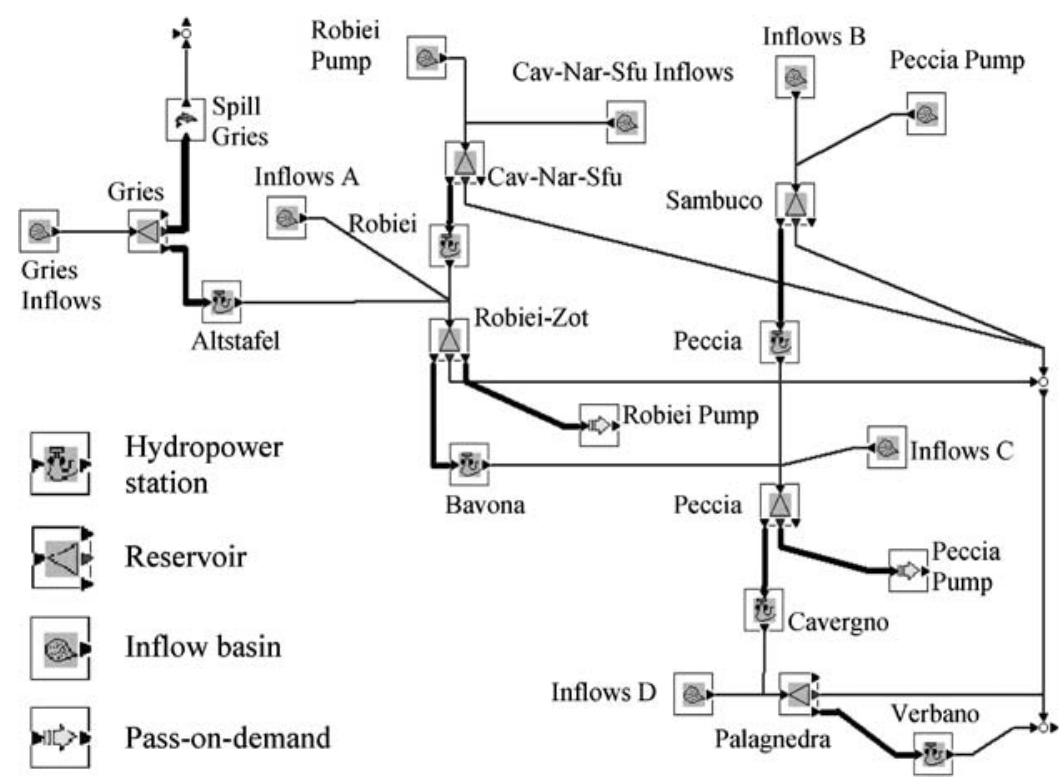

Figure 4. The functional model of the network in the AQUARIUS environment. The bold connections indicate those users that actively demand for water, and thus require that some decisions are taken by the corresponding reservoirs.

\subsection{THE NETWORK MODEL}

The technical data necessary to implement the model has been released by the OFIMA Company and then used upon reciprocal agreement. For the sake of brevity, not all data will be shown here. Hydrological data were obtained from the historical records of the OFIMA Company and from some estimates that were provided by the Swiss Federal Office for Water and Geology (FOWG (2003)), also quoted in the references).

A model of the whole network (Figure 4) was built and then improved in some details, but maintaining the same scheme of Figure 4. Such improvement concerned with a better definition of the relationship between the water level in the reservoir (i.e., the storage) and the energy production rate (Energy Rate Function). The performances of such two models were explored and the related results discussed.

\subsubsection{Inflows to the Reservoirs}

The data for most of the water intakes of the whole network was given for the period September 1993 - December 2003. However, a gap of over six months in the year 1996 affected the records of nearly all the intakes. A restriction to the less interrupted period January 1997-December 2003 was therefore made. These data already accounted for both the water collected by the intakes and the natural inflows due to surface runoff and groundwater. In particular, the net water input 
was calculated starting from the lake level variation and the continuity equation for the reservoir:

$$
\begin{aligned}
& \frac{d V}{d t}-I_{I E}(t)-I_{P k}(t)+O_{I E}(t)+O_{S}(t)+O_{P O}(t)+O_{E}(t) \\
& \quad=I_{A N}(t)+I_{P j}(t)
\end{aligned}
$$

The left hand side part of Equation (7) contains all the known quantities i.e., the lake storage $V(t)$ variation, the inflows due to the upstream power plants $I_{I E}(t)$ and the water intakes $I_{P k}(t)$, the outflows due to controlled releases $O_{I E}(t)$, evaporation $O_{E}(t)$, pumping to upstream reservoir $O_{P O}(t)$ and spills occurring under exceptional events $O_{S}(t)$. The right hand side part contains the unknowns such as natural inflows $I_{A N}(t)$, and eventually not gauged intakes $I_{P j}(t)$. This equation was discretized and used to evaluated the sum of the two unknown terms as a whole, and then the net water input to each reservoir.

The software AQUARIUS requires incoming water inputs as monthly data. Therefore, for every record the corresponding monthly aggregation was made. Small gaps of either missing or erratum data (e.g., these latter exceeding the capacity of the water intake) were filled or adjusted in two different ways depending on the length of the gap itself. In particular, for gaps up to four days a linear interpolation was made, while for longer gaps (up to one month) the corresponding monthly value was assumed to be equal to the monthly mean. However, these adjustments affected only the $2 \%$ circa of the whole data set, and the adopted methodology had an almost negligible influence on the statistics of the original and corrected data. Finally, the 35 water intakes were conveniently grouped so to obtain just one input per reservoir.

\subsubsection{Reservoirs and Lake Evaporation}

For each reservoir AQUARIUS requires the corresponding physical characteristics (i.e., minimum and maximum volume, elevation vs storage and area vs storage functions), the operational ones (i.e., volumes at both the initial $\left(V_{i}\right)$ and end $\left(V_{e}\right)$ period of optimization) as well as the operational constraints (i.e., limiting boundaries in terms of volumes that need to be conserved or not exceeded). Such information is summarized in Table III. The minimum and the maximum storage as well as the conservation of both the initial and final volumes were used as constraints.

Lake evaporation was derived from the average annual values that the FOWG had estimated for the swiss territory. For each lake, AQUARIUS requires the monthly evaporation height, which was calculated by disaggregation of the average annual ones by using appropriate weighting coefficients (Table IV). In particular, these latter were calculated by considering the information coming from the thermometric curve, that is the ratio between the mean monthly and mean annual temperature. Whenever the data of temperature for a given area was not known, then the reading 
Table III. Physical and operational characteristics of the reservoirs as required by AQUARIUS. Elevation vs Storage and Area vs Storage follows a power law relationship $E(A)=$ $a_{1}\left(a_{2}\right) S^{b_{1}\left(b_{2}\right)} \cdot V_{\max }=V_{\text {tot }} ; V_{\min }=V_{\text {tot }}-V_{\text {net }}$ of Table I

\begin{tabular}{lllllll}
\hline Name & $\begin{array}{l}\text { El. vs. St. } \\
a_{1} / b_{1}\end{array}$ & $\begin{array}{l}\text { Ar vs. St. } \\
a_{2} / b_{2}\end{array}$ & $\begin{array}{l}\mathrm{V}_{i} \\
10^{6}\left[\mathrm{~m}^{3}\right]\end{array}$ & $\begin{array}{l}\mathrm{V}_{e} \\
10^{6}\left[\mathrm{~m}^{3}\right]\end{array}$ & $\begin{array}{l}\mathrm{V}_{\min } \\
10^{6}\left[\mathrm{~m}^{3}\right]\end{array}$ & $\begin{array}{l}\mathrm{V}_{\max } \\
10^{6}\left[\mathrm{~m}^{3}\right]\end{array}$ \\
\hline Gries & $19.81 / 0.388$ & $0.124 / 0.586$ & 12.09 & 11.04 & 0.7 & 18.7 \\
Robiei-Zot & $19.74 / 0.434$ & $0.096 / 0.669$ & 3.97 & 6.73 & 2.10 & 8.5 \\
Ca+Na+Sfu & $13.93 / 0.489$ & $0.146 / 0.512$ & 46.95 & 51.71 & 1.30 & 64.50 \\
Sambuco & $6.55 / 0.658$ & $0.176 / 0.453$ & 44.7 & 25.96 & 1.00 & 64.16 \\
Palagnedra & $33.85 / 0.359$ & $0.067 / 0.827$ & 3.09 & 2.54 & 2.25 & 4.25 \\
Peccia & $71.78 / 0.918$ & $0.022 / 0.162$ & 0.01 & 0.01 & 0.00 & 0.11 \\
\hline
\end{tabular}

Table IV. Mean monthly and total annual evaporation height $\mathrm{E}_{\mathrm{m}}[\mathrm{mm}]$ for the lakes

\begin{tabular}{lrrrrrrrrrrrrr}
\hline Lake & J & F & M & \multicolumn{1}{c}{ A } & M & J & \multicolumn{1}{l}{ J } & \multicolumn{1}{c}{ A } & S & O & N & D & Tot \\
\hline Gries & 0 & 0 & 0 & 0 & 19 & 47 & 62 & 74 & 33 & 16 & 0 & 0 & 250 \\
Robiei & 0 & 0 & 0 & 0 & 69 & 117 & 144 & 163 & 93 & 64 & 0 & 0 & 650 \\
Zot & 0 & 0 & 0 & 0 & 69 & 117 & 144 & 163 & 93 & 64 & 0 & 0 & 650 \\
Cavagnoli & 0 & 0 & 0 & 0 & 56 & 140 & 187 & 222 & 98 & 47 & 0 & 0 & 750 \\
Naret & 0 & 0 & 0 & 0 & 49 & 122 & 162 & 192 & 85 & 40 & 0 & 0 & 650 \\
Sambuco & 0 & 0 & 12 & 32 & 93 & 122 & 150 & 155 & 102 & 79 & 6 & 0 & 750 \\
Palagnedra & 20 & 34 & 55 & 69 & 93 & 107 & 121 & 122 & 96 & 72 & 43 & 19 & 850 \\
Sfundau & 0 & 0 & 0 & 0 & 49 & 122 & 162 & 192 & 85 & 40 & 0 & 0 & 650 \\
Peccia & 0 & 5 & 33 & 54 & 94 & 118 & 137 & 135 & 97 & 68 & 13 & 0 & 750 \\
\hline
\end{tabular}

from the closest station was considered, together with the common assumption of $0.65\left[{ }^{\circ} \mathrm{C} / 100 \mathrm{~m}\right]$ of temperature variation with elevation (see, for example Dingman (2002)).

\subsubsection{Power Plants and Economical Benefit Functions}

Technical characteristics of the power plants (Table III) were implemented in the AQUARIUS scheme. In the basic model (hereinafter referred to as model B) the ratio between the storage and the energy production (Energy Rate Function) was kept constant. Such a value was assumed equal to that corresponding to the mean lake storage. The benefit function for this model was fixed as independent on the resource allocation and constant in time for all the plants of the network. This seemed to be consistent with the fact that they belong to the same company. Model $\mathrm{B}$ was then improved by defining a linear trend for the ERF function (hereinafter referred to as model T). This was done for each power plant by means of a linear regression between the data of energy production vs turbinated water and the storage history of the corresponding reservoir. 
The monthly pumping schedule is usually concentrated in periods with low energy demand (e.g., weekends and summer season). Since the pumping mechanism cannot be implemented in the present version of AQUARIUS, an ad hoc strategy was therefore adopted here in order to take such an effect into account. Water was taken out of the compensation reservoir by using the 'pass-on-demand' object, and at the same time it was re-injected in the upstream reservoir. This was done for both the Robiei-Zot and the Peccia reservoirs. Pumping rates were set constantly equal to the average calculated on the available data. The costs of pumping were not straight accounted for, but this issue was however overcome by taking the gross energy production under consideration. Given the different time scale of both the process and the analysis, this method allowed us to simulate the actual situation quite reasonably.

\section{Discussion of the results}

\subsection{MODELS RESULTS ON THE HISTORICAL DATA}

The model shown in Figure 4 does not have multiple users connected to the same decision node (e.g., a reservoir), but rather numerous parallel and cascade interconnections between the power stations and the reservoirs. As a consequence, a true competitive strategy of optimization between the water uses (i.e., based on the reallocation of the resources until an equal marginal value of resource is the same for each user) cannot develop in the sense given by Diaz et al. (1992). The operational and physical constraints will instead play a strong role on the allocation of the resource, and the optimization will be thus markedly influenced by the shape of the ERF function. Both the model were first tested on the monthly historical data covering the period of seven years above mentioned. This allowed to check the performances of each model and afterwards to provide a useful comparison for other simulations.

A first comment on the real production is necessary. The monthly average over the analyzed period (1997-2003) showed an almost limited variance of the external demand (Figure 5). Model B run on the same data showed a behaviour similar to that of the real network. However, it also gave a nearly $10 \%$ higher average production than the real one. To a certain extent although these conclusions are not surprising they cannot be interpreted as a straight results of the optimization. Indeed, there are at least two main justifications to explain them. First of all, by excluding the presence of errors in the inflows, then the higher production could be related to the possible presence of water losses (e.g., within the galleries), which are not accounted for by AQUARIUS. Secondly, the assumption of a constant value for the ERF is too unrealistic and this explains the low monthly variance of the energy production. In facts, since the solution does not aim at high reservoir storage states, then the whole system has no reasons to find a monthly dependent allocation of the resource. As a consequence, a first interesting conclusion can be already drawn. That is, performances of model B are limited at interpreting every solution as an 


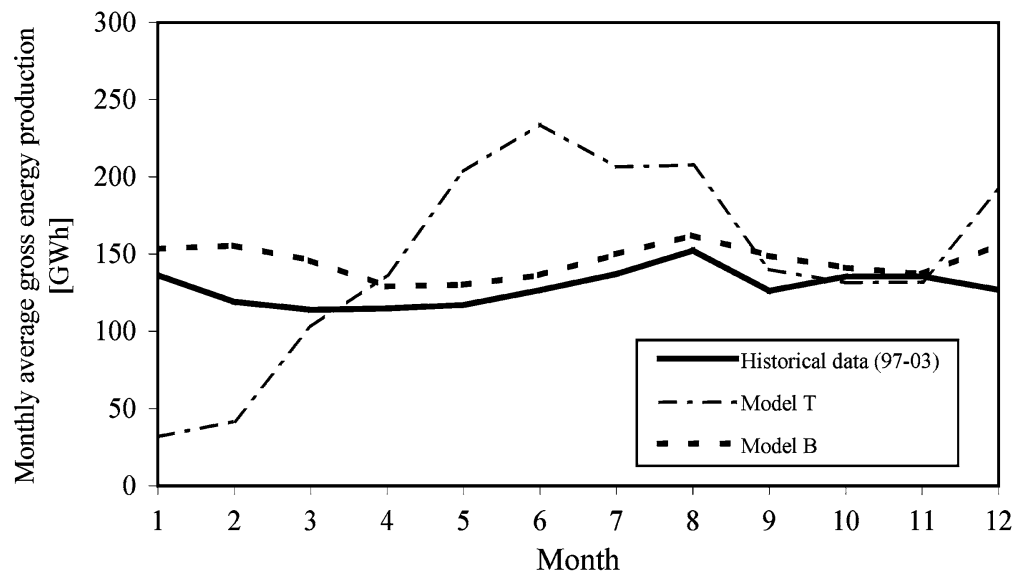

Figure 5. Monthly average of the gross energy production for the historical data and the models at optimality.

optimal one although they would apparently reflect the effects caused by a nearly constant external demand on the real network.

In order to make model B realistic, the physical meaning of the ERF function cannot be neglected and the introduction of a non constant relationship is therefore needed (i.e., model T). For each power station, a linear regression between the energy production vs turbinated water ratio and the storage records of the related upstream reservoir was fitted using the historical data. Notice that in doing this the mean of the regression was equal to the constant ERF values used for model B. In one case (i.e., Peccia hydropower station) such a function was assumed to be constant, given the limited volume of the corresponding reservoir (i.e., $\sim 0.1 \mathrm{Mcm}$ ). From Figure 5 the redistribution of the energy production around the summer months i.e., where there is a greater availability of the water resource is now evident. At optimality, an increase in the average production of about $1.5 \%$ respect to that of model B was also observed despite the quantity of the turbinated water was the same over the whole optimization period. Although this happened thanks to the assumption made for the ERF relationship, the actual significance of the optimization process is better quantified by the shape of the new allocation rather than the magnitude. The model allocated the water in correspondence of the higher states of the reservoirs (Figure 6), which explains the increase in the production. Therefore, the linear ERF allowed the system to consider the maximum storage as a preferential state for the whole network dynamics. This happened especially for the downstream reservoirs since they receive all the water from the upper plants and have a greater probability of fluctuating around the maximum reservoir capacity. Conversely, reservoirs in the upper valley can only allocate water depending on the incoming flows, and their efficiency does not result affected too much from the more detailed description of the energy vs storage curve. 


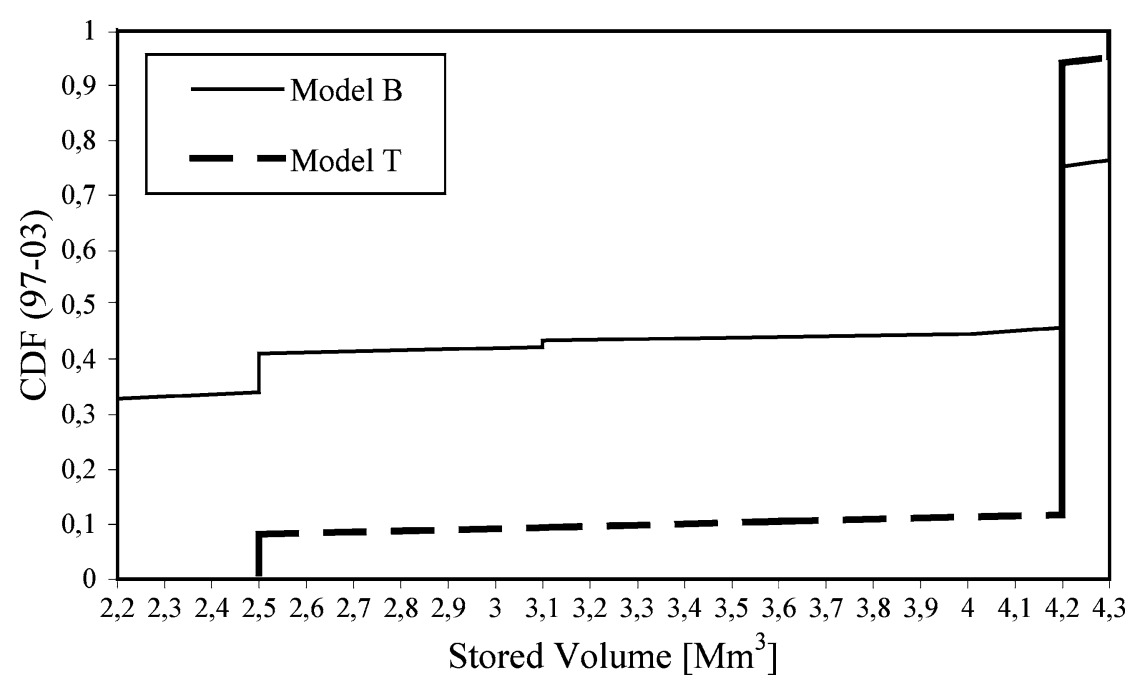

Figure 6. Cumulated distribution function of the optimal stored volumes suggested by the models for the Palagnedra reservoir in the period 1997-2003.

\subsection{EFFECTS OF INFLOWS CHANGES AND ENVIRONMENTAL FLOW RELEASE}

Along with the results discussed above it is now interesting to comment the behaviour of the network in the presence of changes in the inputs. This aspect can be relevant for future questions regarding the influence of either climatic variations or decisions affecting the environmental flow release. In order to explore such cases, the main working hypothesis concerned with the implementation of the pumping effects. As a first approximation, these were maintained equal to the historical ones for all the analyzed cases.

\subsubsection{Changes in Input Magnitude}

Starting from the historical data a new set of statistically equivalent inflows was generated for every reservoir of the AQUARIUS network. New data generation was done by perturbing the monthly average with errors having statistical properties equal to that of the historical ones. In particular, the statistics of the errors around the current mean were approximated to be gaussian. More proficient techniques could have been used (e.g., periodic autoregressive stochastic models), but their implementation would not have brought a greater advantage given the mainly explorative purposes of the paper, the monthly time scale of analysis (which implies an aggregation of daily data), and the relative limited length of the initial database (i.e., seven years). The new set of data was thereafter used as new reference time series. Other series were then produced by either increasing or decreasing the magnitude of the surrogated series of a percentage varying in the range $[-20 \div 20] \%$ with intervals of $5 \%$. The hypothesis of proportional increasing or decreasing of the magnitude maintains the shape of the series. Therefore, for the upper reservoirs 


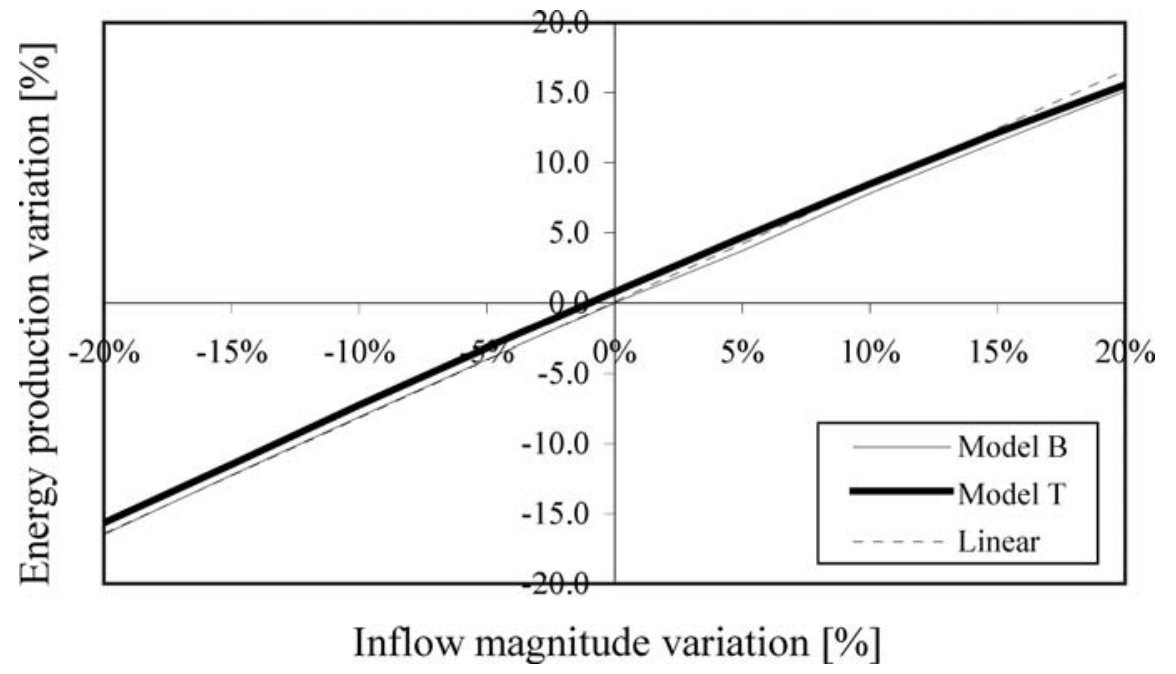

Figure 7. Differences in the total energy production over a period of 7 years for changes in the inflows magnitude. The dashed line indicates proportionality.

the distribution of the inputs will still reflect the mechanism of accumulation and storage of the solid precipitation as the presence of glaciers as well. These characteristics allow some hints on both the robustness of the software and the response to possible changes in the precipitation regime to be obtained. Figure 7 shows the total energy production of both model $\mathrm{B}$ and model $\mathrm{T}$ over a period of 7 years. Both models responded linearly when the magnitude was decreased, whilst a weak nonlinear response appeared when precipitation was increased. This is mainly due to the saturation of the production capacity of the turbines and, in turn, to the consequent spilling of the reservoirs. However, provided one works at optimality, linearity in the production seemed to hold up to increases of the order of $10 \%$, thus suggesting a good flexibility of the real network against such events. The diagram in Figure 8 shows the mean monthly energy production for the two limiting cases at $\pm 20 \%$. At the optimality, the production of model T peaked around the spring period if precipitation was reduced. This is also consistent with the occurrence of the melting period and its duration is therefore limited. Conversely, the greater the availability of water, the longer the period of maximum production, as expected. Model B still gave a nearly constant production as if it was forced to produce more or less constantly during the year.

\subsubsection{Changes in the Environmental Flow Requirements}

Along with the ongoing questions directed to understanding the role of the environmental flow releases on the fluvial ecosystem health (Benjamin and Van Kirk, 1999, Whipple et al., 1999, Nilsson and Svedmark, 2002, Huges and Rood, 2003), both the models were asked to optimize the production under different augmented 


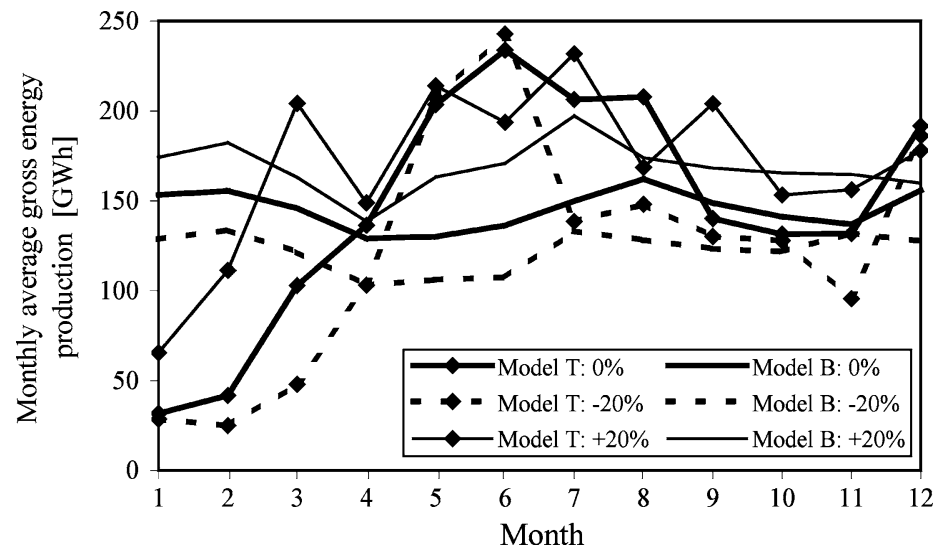

Figure 8. Monthly average of the gross energy production suggested by the two model at the optimum for the two extreme cases of changes in the inflows magnitude.

releases of water to the river. Although AQUARIUS would be in principle able to handle a competition between such uses, the present version of the software has not implemented yet the riparian vegetation as possible competitor. Moreover, the monthly time step of analysis would also smooth the impact of the water allocation resulting from the competition between hydropower and vegetation. Therefore, the problem was by-passed by directly releasing to the river a portion of the water turbinated by the Cavergno station. Such a situation seemed to be quite realistic and was recreated by reducing the inflows to the Palagnedra reservoir. Results, which are shown in Table V, would indicate that a nearly linear decreasing in the energy production can be expected, provided the operating rules meet with the suggested optimal strategy. However, the interesting result is that of Figure 9: at optimality, the percentage difference in the energy production are strongly monthly dependent. Again this is particularly evident for model $\mathrm{T}$, which solution allowed to generate more energy with respect to model B.

Table $V$. Relative variation in the annual energy production in response to augmented environmental flow releases respect to the actual ones $\left(1.2 \mathrm{~m}^{3} / \mathrm{s}\right.$ in winter and $1.8 \mathrm{~m}^{3} / \mathrm{s}$ in summer)

\begin{tabular}{lll}
\hline $\begin{array}{l}\text { Additional release } \\
{\left[\mathrm{m}^{3} / \mathrm{s}\right]([\mathrm{Mcm} / \text { year }])}\end{array}$ & $\begin{array}{l}\text { Model B } \\
\%\end{array}$ & $\begin{array}{l}\text { Model T } \\
\%\end{array}$ \\
\hline $0.5(15.8)$ & -0.4 & -0.4 \\
$1(31.5)$ & -0.9 & -0.8 \\
$1.5(47.3)$ & -1.3 & -1.3 \\
$2(63.1)$ & -1.8 & -1.7 \\
$2.5(78.8)$ & -2.3 & -2.2 \\
\hline
\end{tabular}




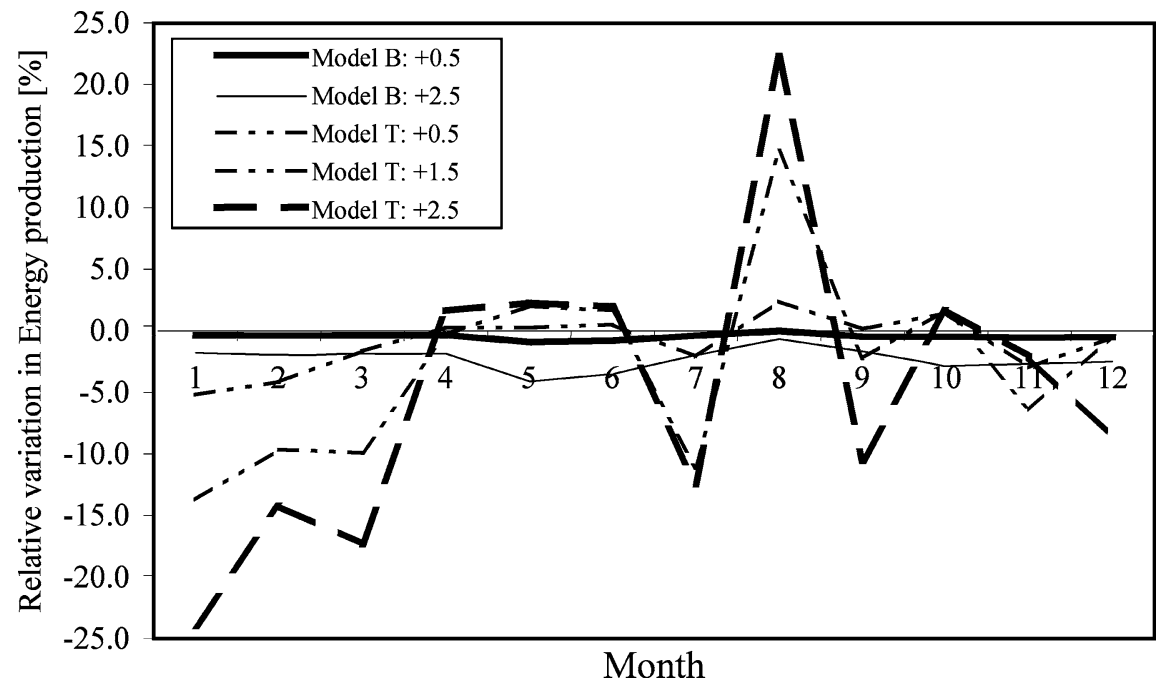

Figure 9. Monthly relative variation in the total energy production under changes of environmental requirements.

\section{Conclusions}

Optimal water allocation in the hydropower plants network of the Maggia Valley was investigated in this work. The nonlinear optimization problem in response to changes in the production policy and to climatic and environmental factors was tackled here by means of the software AQUARIUS. Within this case study, and despite some limitation of the software, the importance of planning the operational rules in advance under changing scenarios was thus shown. The cases investigated were mainly hypothetical, but they provided evidence of how the optimal solution should be re-adjusted in the case of a production policy that privilege a free global market in spite of a local one. In particular, provided that one works at optimality the AQUARIUS model suggested that (1) under the perspective of a new production policy the new monthly energy production distribution can be even markedly different from the actual one; (2) notwithstanding this, thanks to the basic structure of the hydropower network the optimal conditions are not restrictive too much, so that the real network would still produce a global returning benefit that is still competitive with the present one; 3 ) the real network appeared to be quite flexible also against increasing inflows to the reservoirs or augmented environmental requests, thus proving the adequacy of the current hydropower network to handle with such different scenarios.

Among the factors that make the use of the software still limited, there are the restrictive monthly time step of analysis, the absence of pumping in the hydropower water use, and the lack of an appropriate water use to represent the riparian vegetation requests. The hope is that such missing points will soon be 
fulfilled. Improvements of the aforementioned performances of AQUARIUS will therefore be very welcome especially in the light of future studies directed to analyze more realistic scenarios and to widen the use of this software to audiences not necessarily research oriented.

\section{Acknowledgements}

This work was completed during the Master program of one of the authors (L.A.), who took advantage of numerous contacts with the OFIMA Company. People of the staff are therefore gratefully acknowledged for their kind disposal in both providing data, technical information, and some clarificant explanations. Gustavo Diaz is also acknowledged for useful hints about the software AQUARIUS, as well as the reviewers for their constructive comments. This work was partially funded by the Swiss National Foundation (SNF) grant number 21-66885.

\section{References}

Benjamin, L. and Van Kirk, R. W., 1999, 'Assessing instream flows and reservoir operations on Eastern Idaho River', Journal of the American Water Resources Association 35(4), 899-909.

Brown, T. C., Harding, B. L., and Payton, E. A., 1990, 'Marginal economic value of streamflow: A case study for the Colorado River basin', Water Resources Research 26(12), 28452859.

Brown, T. C., Diaz, G. E., and Sveinsson, G. B., 2002, 'Planning water allocation in river basins, Aquarius: A system's approach', Proceedings of 2nd Federal Interagency Hydrologic Modelling Conference, Subcommittee on Hydrology of the Advisory Committee on Water Information, Las Vegas, NV, (available on line at http://www.fs.fed.us/rm/value/aquarius.html).

Bushaw-Newton, K. L., Hart, D. D., Pizzuto, J. E., Thomson, J. R., 2002, 'An integrative approach towards understanding ecological responses to dam removal: The Manatawny Creek study', Journal of the American Water Resources Association 38(6), 1581-1599.

Diaz, G. E., Brown, T. C., and Morel-Sejtoux, H. J., 1992, 'The marginal economics value of streamflows: A systemic approach', Hubert J. Morel-Sejtoux, editions, 419 p. Proceedings of American Geophysical Union Twelfth Annual Hydrological Days, Colorado State University, Forth Collins, CO, Published by the Hydrology Days Publications, California 94027 (available on line at http://www.fs.fed.us/rm/value/aquarius.html).

Diaz, G. E. and Brown, T. C., 1997, 'Aquarius: A general model for efficient water allocation in river basins', Proceedings of 27th Congress of the International Association for Hydraulic Research, Theme A: Managing Water: Coping with Scarcity and Abundance, San Francisco, CA, Published by the American Society of Civil Engineers, NewYork (available on line at http://www.fs.fed.us/rm/value/aquarius.html).

Diaz, G. E., Brown, T. C., and Sveinsson, O., 1997, 'Aquarius: A modeling system for river basin water allocation', General Technical Report RM-GTR-299, 172p. U.S. Department of Agriculture, Forest Service, Rocky Mountain Forest and Range Experiment Station, Fort Collins, CO, USA, (available online at http://www.fs.fed.us/rm/value/aquarius.html).

Dingman, S. L., 2002, Physical Hydrology, Second Edition, Prentice Hall, New Jersey.

Federal Office for Water and Geology (FOWG), 2003, Swiss yearbooks of hydrology, UFCL publications, CH-3003 Bern.

Fletcher, R., 1980, Practical methods of optimization. Vol. 2: Constrained optimization, John Wiley $\&$ Sons. 
Franković, B., 1994, 'Impact of the Drava River reservoirs on groundwater', Proceedings of the Dixhuitième Congrès des Grands Barrages, Durban, Published by the Commissio International Des Grands Barrages.

Frederick, K. D. andSchwarz, G. E., 1999, 'Socioeconomic impacts of climate change on U.S. water supplies', Journal of the American Water Resources Association 35(6), 1563-1583.

Hickey, J. T. and Diaz, G. E. , 1999, 'From flow to fish to dollars: An integrated approach to water allocation', Journal of the American Water Resources Association 35(5), 1053-1067.

Hughes, F. M. R. and Rood, S. B., 2003, 'Allocation of river flows for restoration of floodplain forest ecosystem: A review of approaches and their applicability in Europe', Environmental Management, 32(1), 12-33.

Jordan, J. L., 1999, 'Externalities, water prices, and water transfers', Journal of the American Water Resources Association 35(5), 1007-1013.

Nilsson, C. and Svedman, M., 2002, 'Basic principles and ecological consequences of changing water regimes: Riparian plant communities', Environmental Management 30(4), 468-480.

Pohl, M. M., 2002, Bringing down our dams:trends in american dam removal rationales, Journal of the American Water Resources Association 38(6), 1511-1519.

Snelder, T. H. and Biggs, B. J. F., 2002, 'Multiscale river environment classification for water resources management', Journal of the American Water Resources Association 38(5), 1225-1239.

Whipple, W. Jr., DuBois, D., Grigg, N., Herricks, E., Holme, H. et al., 1999, 'A proposed approach to coordination of water resources development and environmental regulations', Journal of the American Water Resources Association 35(4), 713-716. 